\title{
Leukaemia, lymphoma, and multiple myeloma in seamen on tankers
}

\author{
Ralph I Nilsson, Rolf Nordlinder, Lars-Gunnar Hörte, Bengt Järvholm
}

\section{Department of Occupational Medicine, Sahlgrenska University Hospital, S:t Sigfridsgatan 85 , HSE-412 66 Göteborg, Sweden R I Nilsson $\mathrm{R}$ Nordlinder B Järvholm}

Department of International

Health and Social Medicine Safety Promotion Unit, Sturegatan 2, HSE-172 83

Sundbyberg Sweden, and Institute of

Forensic Medicine, University of Uppsala, Uppsala, Sweden L-G Hörte

Department of Occupational and Environmental

Medicine, Umeå University, HSE-901 85 Umeå, Sweden B Järvholm

Correspondence to: Dr Ralph Nilsson, Department of Occupational Medicine, Sahlgrenska University Hospital, S:t Sigfridsgatan 85 , HSE-412 66 Göteborg, Sweden.

Accepted 12 January 1998

\begin{abstract}
Objectives-To investigate the risk of lymphatic and haematopoietic malignancies in deck crew on tankers exposed to cargo vapours.

Methods-The study design was as a nested case-referent study in two cohorts of male Swedish seamen 20-64 years of age at the national census 1960 (n 13 449) and 1970 (n 11 290), respectively. Cases were detected by record linkage with the Swedish Cancer Register 1961-79 and 1971-87, respectively. For each case, three to five age matched referents from the population were selected. Exposure was assessed from data in the Swedish Registry of Seamen and from a register of Swedish ships. Results-Seamen in the 1970 cohort, who had been exposed to cargo vapours for at least one month on chemical or product tankers, had an increased risk of lymphatic and haematopoietic malignancies (Mantel-Haenszel odds ratio (OR) 2.6, $95 \%$ confidence interval $(95 \%$ CI) 1.1 to 5.9)) with a significant exposure-response relation (conditional logistic regression analysis, $p=0.04)$. The ORs were increased for both lymphoma (3.2), multiple myeloma (4.0), and leukaemia (1.6), but the increase was only significant for nonHodgkin's lymphoma (OR 3.3, 95\% CI 1.1 to 10.6). There were no significantly increased risks for the 1960 cohort or for seamen exposed only on crude oil tankers, but these groups had few exposed cases and low cumulative exposure to benzene and other light petroleum products.

Conclusions-Seamen exposed to cargo vapours from gasoline and other light petroleum products on chemical or product tankers had an increased incidence of lymphatic and haematopoietic malignancies. One possible cause is exposure to benzene during loading, unloading, and tank cleaning operations.

(Occup Environ Med 1998;55:517-521)
\end{abstract}

Keywords: benzene; cancer; occupation

We have previously reported two cases of acute non-lymphatic leukaemia among mates on tankers who had been exposed to benzene from cargo vapours. In two articles from Norway, mates on tankers were reported to have increased morbidity and mortality from cancer. $^{23}$

The deck crew on chemical and product tankers can be exposed to high concentrations of cargo vapours. Product tankers carry mainly petroleum products such as gasoline, diesel oil, and fuel oils whereas a wide range of chemicals and petroleum products are transported on chemical tankers. ${ }^{45}$ Benzene concentrations up to some $100 \mathrm{ppm}$ have been measured during tank cleaning, loading, and unloading of gasoline and some other light refinery products. ${ }^{6-8}$ Benzene is a well known leukaemogen ${ }^{9}$ and has also been suspected to cause other malignancies such as lymphoma, including multiple myeloma. ${ }^{10-13}$ The results of a large benzene cohort study, recently published, showed a significant excess of leukaemia and lymphoma and a significant trend in the dose-response for both of these types of cancer separately. ${ }^{14}$

The objective of this study was to investigate whether work on deck on tankers, especially chemical and product tankers, is associated with an increased risk of lymphatic and haematopoietic malignancies. In a nested casereferent study the exposure was estimated from type of job and type of ship.

\section{Methods}

STUDY DESIGN AND SUBJECTS

This is a nested case-referent study of Swedish seamen with two study bases. In the population and housing censuses 1960 and 1970 Swedish citizens were asked about their occupation at the time of the census. The two studied populations are men, 20-64 years of age, registered as seamen (deck and engine room crew) (codes 601-611 in the Nordic Classification of Occupation) at the National Censuses in Sweden 1960 and 1970 respectively. In all 13449 and 11290 men fulfilled these criteria.

Cancer cases were available from linkages between the censuses and the Swedish $\mathrm{Na}$ tional Cancer Register. A potential case in this study is defined as a seamen in the census of 1960 or 1970, who had a lymphatic or haematopoetic malignancy (ICD8 200-207). Due to restriction on linking census data, we used two already available links. The Swedish Cancer Environment Register 1960 (CER60) is a link between the 1960 census and the Cancer Register for the period 1961-79. The CER70 is a link between the 1970 census and the Cancer Register for the period 1971-87. The two study bases thus partially overlap.

For each case, three to five potential referents were randomly selected from the same 5-year birth year stratum among men classified as seamen in the same National Censuses. All potential referents were checked against the National Cause of Death Register as the referent had to be alive at the year of diagnosis of the case.

A case or a referent also had to have a record in the Swedish Registry of Seamen. In this 
Table 1 Relative risks * for lymphatic and haematopoietic malignancies in Swedish seamen exposed to cargo vapours on tankers

\begin{tabular}{|c|c|c|c|c|c|}
\hline \multirow[b]{2}{*}{ Diagnosis (ICD-8) } & \multirow{2}{*}{$\begin{array}{l}\text { Total cases } \\
n\end{array}$} & \multicolumn{2}{|c|}{ Chemical or product tanker } & \multicolumn{2}{|c|}{ Crude oil tanker, only } \\
\hline & & $n$ & OR $(95 \% C I)$ & $n$ & $O R(95 \% C I)$ \\
\hline \multicolumn{6}{|l|}{1960 cohort (1961-79): } \\
\hline Lymphoma (200-202) & 22 & 4 & $1.8(0.5$ to 6.5$)$ & 0 & 0 \\
\hline Non-Hodgkin's $(200,202)$ & 17 & 4 & $4.0(0.9$ to 18.9$)$ & 0 & 0 \\
\hline Hodgkin's (201) & 5 & 0 & 0 & 0 & 0 \\
\hline Myeloma (203) & 6 & 0 & 0 & 0 & 0 \\
\hline Leukaemia (204-207) & 18 & 2 & $0.9(0.1$ to 5.8$)$ & 4 & $2.4(0.8$ to 7.4$)$ \\
\hline All (200-207) & 46 & 6 & $1.1(0.4$ to 3.1$)$ & 4 & $0.6(0.2$ to 1.7$)$ \\
\hline \multicolumn{6}{|l|}{1970 cohort (1971-87): } \\
\hline Lymphoma (200-202) & 27 & 9 & $3.2(1.2$ to 9.0$)$ & 3 & $0.6(0.2$ to 2.4$)$ \\
\hline Non-Hodgkin's $(200,202)$ & 20 & 6 & $3.3(1.1$ to 10.6$)$ & 3 & $0.9(0.2$ to 4.0$)$ \\
\hline Hodgkin's (202) & 7 & 3 & $3.0(0.4$ to 22.5$)$ & 0 & 0 \\
\hline Myeloma (203) & 7 & 1 & $4.0(0.1$ to 161$)$ & 0 & 0 \\
\hline Leukaemia (204-207) & 12 & 4 & $1.6(0.4$ to 6.0$)$ & 1 & $0.6(0.1$ to 5.4$)$ \\
\hline All (200-207) & 46 & 14 & $2.6(1.1$ to 5.9$)$ & 4 & $0.5(0.1$ to 1.4$)$ \\
\hline
\end{tabular}

^Mantel-Haenszel ORs (95\% CIs).

†Exposure = work as a mate, boatswain, able seaman, or pumpman on a tanker at least one month before the year of diagnosis.

registry, which is held mainly for pension purposes, all positions held, including the name of the ships, and employment times, have been registered for all seamen working on Swedish ships. Eighty four per cent of the cases and referents from the linkages had a record in this registry.

In total 46 cases and 159 referents from CER60 and 46 cases and 132 referents from CER70 fulfilled the inclusion criteria. Eleven cases occurred both in CER60 and CER70 and were counted in both groups.

\section{EXPOSURE}

Data on times of service (dates, number of days), occupational category, the name of the ship, and the shipowner were collected from the Swedish Registry of Seamen.

The ship was then classified in one of three categories: chemical or product tanker; crude oil tanker; other-for example, ferry, general cargo, etc. This classification was based on information from a private register of Swedish ships (Walter Nilsson, Helsingborg). Through a random sample of 100 ships the classification was checked against a register held at the Swedish Shipowners' Association. All ships in the sample were classified in the same way in both registers.

The seaman was classified as exposed to cargo vapours, if he had worked for at least one month as a mate, boatswain, able seaman, or pumpman on a chemical tanker, product tanker, or crude oil tanker, which included oilbulk-ore tankers. Work in other occupations or on other types of ships was classified as unexposed. Those who were exposed only on crude oil tankers or oil-bulk-ore tankers were analysed separately as exposure to cargo vapours were considered to be lower on these tankers, due to a lower frequency of loading and unloading.

Each calendar month of the employment periods on ships was categorised as exposed or unexposed by an occupational hygienist. The exposure classification was done without knowledge of case-referent status. The referents were assigned the same year of diagnosis as the case. Only exposed months before the year of diagnosis for a case and the corresponding referents were considered in the analysis.
DATA ANALYSES

The analyses were done separately for CER60 and CER70. Stratified analyses were done with the statistical software package SAS (version 6.08). In the stratified analysis-that is, Mantel-Haenszel estimate- each case and referent were stratified according to year of birth (five-year intervals) and year of diagnosis (1961-70, 1971-9, 1971-80, and 1981-7). Conditional logistic regression for analysis of matched sets was done with the EGRET statistical software package.

\section{Results}

In the 1970 cohort increased risks for lymphoma, multiple myeloma, and leukaemia were found for those who had worked on deck on chemical or product tankers, although the results were only significant for lymphoma and for all lymphatic and haematopoietic malignancies together (table 1). We found no significantly increased risks in the analysis based on 1960 cohort, but the $95 \%$ confidence intervals ( $95 \%$ CIs) were wide due to the few exposed cases.

All cases of leukaemia in the group exposed to cargo vapours on chemical or product tankers were of the chronic lymphocytic type, except one case of unspecified myeloid type in the CER70 cohort. The Mantel-Haenszel odds ratio (OR) for chronic lymphocytic leukaemia (CLL) in the CER70 cohort was 3.9 (95\% CI 0.7 to 21.1 ).

Comparatively few cases were exposed only on crude oil tankers (table 1). The ORs were generally lower for work on crude oil tankers than for work on chemical or product tankers, except for leukaemia in the 1960 cohort.

There was a positive exposure-response relation for all lymphohaematopoietic malignancies in the 1970 cohort (table 2). The association between the risk of developing a lymphohaematopoietic malignancy and the number of exposed months before the year of diagnosis was significant in the conditional logistic regression analysis $(p=0.04$, likelihood ratio statistic). The ORs changed marginally when including a 5-year latency period, but the numbers of exposed cases were too small to make analysis by latency period feasible. 
Table 2 Relative risks * for lymphatic and haematopoietic malignancies (ICD-8 200-207) in Swedish seamen for different exposuret times and latency times

\begin{tabular}{|c|c|c|c|c|}
\hline \multirow[b]{2}{*}{ Exposure time (months) } & \multicolumn{2}{|c|}{ No latency } & \multicolumn{2}{|c|}{ Latency $\geqslant 5$ years } \\
\hline & $n$ & OR $(95 \% C I)$ & $n$ & OR $(95 \% C I)$ \\
\hline \multicolumn{5}{|l|}{1960 cohort (1961-79): } \\
\hline Exposed $\geqslant 1$ & 6 & $1.1(0.4$ to 2.8$)$ & 5 & $0.9(0.3$ to 2.6$)$ \\
\hline $1-6$ & 2 & $0.9(0.2$ to 4.5$)$ & 2 & $1.0(0.2$ to 5.1$)$ \\
\hline $6-12$ & 2 & $0.9(0.2$ to 4.7$)$ & 1 & 0.5 (0.1 to 3.8$)$ \\
\hline$>12$ & 2 & $1.5(0.3$ to 8.5$)$ & 2 & $1.5(0.3$ to 8.3$)$ \\
\hline \multicolumn{5}{|l|}{1970 cohort (1971-87): } \\
\hline Exposed $\geqslant 1$ & 14 & $2.4(1.1$ to 5.3$)$ & 11 & $1.7(0.8$ to 3.9$)$ \\
\hline $1-6$ & 5 & $1.9(0.6$ to 6.0$)$ & 5 & $1.5(0.5$ to 4.5$)$ \\
\hline $6-12$ & 2 & $6.1(0.5$ to 70$)$ & 1 & $2.8(0.2$ to 47$)$ \\
\hline$>12$ & 7 & $2.4(0.9$ to 6.9$)$ & 5 & $1.9(0.6$ to 6.1$)$ \\
\hline
\end{tabular}

${ }^{\star}$ Logistic ORs $(95 \% \mathrm{CI})$.

tWork as a mate, boatswain, able seaman, or pumpman on a chemical or product tanker before the year of diagnosis. little statistical power to detect excesses of specific cell types of leukaemia.

A differential reporting of exposed or non-exposed seamen to the Cancer Register seems improbable. All cases of cancer in Sweden have to be reported to the National Cancer Register. An investigation showed that about $12 \%$ of cases of leukaemia or multiple myeloma were not reported to the Register. ${ }^{16}$ This is somewhat higher than for most other malignancies.

One of the two index cases ${ }^{1}$ was treated in a Swedish hospital but was not reported to the Cancer Register, and was, thus, not included in this study. Exclusion of the other index case resulted only in marginal changes of the ORs for the 1970 cohort (all lymphatic and haematopoietic malignancies OR 2.5, 95\% CI 1.1 to 5.8; leukaemia OR $1.3,95 \%$ CI 0.3 to 5.2 ).

The data in the population and housing censuses in Sweden 1960 and 1970 are considered to be reliable. The misclassification of occupation in the sector of transport and communication work was about $14 \%$ in the 1960 census, ${ }^{17}$ which is somewhat higher than for most other occupations.

As this is a nested case-referent study in which both cases and referents were selected among the same study population of seamen it is likely that the mis-classification of both diagnosis and occupation is non-differential. The classification of exposure was based on occupational titles in a register as well as on the categorisation of boats. Furthermore, the classification was blinded with regard to case-referent status. The requirement that the referent should be alive at the time of diagnosis of the case tends to somewhat overestimate the exposure among referents, leading to conservative estimates of the risks.

Engine room personnel with possible exposure to oils, diesel exhaust, and some cleaning chemicals were included among the referents. If they had an increased incidence of lymphohaematopoietic malignancies, this would also tend to lower the risk estimates for the exposed group. Exclusion of engine room personnel from the material resulted in somewhat lower ORs and wider confidence intervals. Thus, it is not likely that these exposures increased the risks for lymphatic or haematopoietic cancers.

We have only information on occupation for cases and referents for the time periods they have worked as seamen on Swedish ships. Other relevant exposure could have led to misclassification of exposure, which probably is non-differential, thus leading to risk estimates closer to unity.

The numbers of exposed cases of lymphatic and haematopoietic cancers were small $(n=6$ in the 1960 cohort and $n=14$ in the 1970 cohort), which make the power to detect an increased risk low, especially in the 1960 cohort. Despite this, we found a significantly increased rate ratio in the 1970 cohort, which was supported by a significant dose-response relation.

\section{CAUSES OF INCREASED RISKS}

The increased risk could be caused by exposure to cargo vapours containing, for
The number of exposed cases, especially of leukaemia, was small in this study. It has, thus, 
example, benzene. Product tankers carry mainly petroleum products, whereas a wide range of chemicals, including petroleum products - such as gasoline-are transported on chemical tankers. For most hazardous chemicals there are safety regulations which restrict the exposure, whereas gasoline and other petroleum products were often loaded with the hatches open. The main exposure on chemical tankers is thus to hydrocarbons from petroleum products. ${ }^{4} \mathrm{We}$, therefore, decided to include these in the same group as product tankers.

Mates and able seamen on chemical and product tankers could be exposed at least during short periods to high concentrations of cargo vapours containing benzene from gasoline or other petroleum products during loading or unloading. ${ }^{6-8}$ On crude oil tankers, the exposure to benzene, for example, is considerably lower than on product tankers, and the risk estimates were also generally lower for work on crude oil tankers.

Benzene is an established cause of leukaemia and has also been suspected to cause other lymphohaematopoietic malignancies such as lymphoma, especially non-Hodgkin's lymphoma, and multiple myeloma..$^{9-14}{ }^{18-20}$ The association between benzene exposure and leukaemia has been most convincingly shown for acute myeloid leukaemia (AML). It has been a matter of debate whether exposure to benzene is also associated with other cell types of leukaemia. ${ }^{13}{ }^{14}$ 19-21 A comparatively large cohort study of chemical workers showed significant dose-response relations between cumulative exposure to benzene and excess mortality from leukaemia, as well as the broader category of all lymphatic and haematopoietic cancer, although there was no death from AML. ${ }^{22}$ It has been suggested that high exposure to benzene predominantly causes AML, whereas chronic low grade or intermittent exposure to benzene, especially together with other aromatic hydrocarbons, may cause other forms of leukaemia and lymphoma. ${ }^{23}$ In a study of rubber workers, the risk of death from lymphatic leukaemia was about 7 for workers in jobs with high exposure to solvent (compared with other workers), and about twofold in jobs with medium or light exposure to solvents. ${ }^{24}$ The power to detect an increased risk of AML, or any specific type of leukaemia, or non-Hodgkin's lymphoma in our study is low as there are only a few exposed cases.

In this study we cannot separate the effect of exposure to benzene and to other chemicals in cargo vapours (mainly aromatic and aliphatic hydrocarbons) as these exposures are highly correlated. We have, however, not found any convincing evidence in the literature that other constituents of petroleum products could cause lymphatic or haematopoietic malignancies.

Moen et al found a significantly increased morbidity and mortality of cancer in seamen who had been working as mates on Norwegian tankers, especially oil tankers. ${ }^{2}$ Work as a captain was not associated with any significantly increased risk. The risks for lymphatic and haematopoietic malignancies were not calculated separately.

No increased mortality from leukaemia was found in a study of distribution employees with potential exposure to gasoline on marine vessels in the United States, but there was a non-significant mortality increase for AML (SMR 150.5) in land based terminal employees. ${ }^{25}$ However, the SMR for all causes was low, especially for land based cohort members (SMR 51). According to the authors, this was probably due to selection at time of hire, and when compared with the general population, better health maintenance, less smoking, less drinking, and higher socioeconomic status.

The benzene content of gasoline, which is one of the main cargoes transported on product tankers, is generally $<1.5 \%$ in the United States compared with about $2 \%-4 \%$ in Sweden and England. Yet a study of gasoline station attendants in the United States showed a significant excess of leukaemia ${ }^{26}$ and case reports indicated leukaemia cases related to gasoline exposure in the United States. ${ }^{27}$ Tanker drivers exposed to gasoline with relatively low levels of benzene showed significantly increased mortality due to leukaemia in a Canadian study. ${ }^{28}$

The increased risk was only significant in the analysis of the 1970 cohort data. In the 1960 cohort, there were only a few exposed cases, making risk estimates imprecise. The difference in risk between 1960 and 1970 cohorts may possibly be due to difference in exposure. The transportation of gasoline on tankers has increased considerably since 1960, especially when compared with fuel oils, which also are transported on product tankers. The amount of gasoline unloaded in Swedish harbours was $>300 \%$ higher in 1980 when compared with $1960 .{ }^{29}{ }^{30}$ The exposure to benzene, for example, is thus probably substantially higher for the exposed group in the 1970 cohort.

The exposure to cargo vapours has probably decreased during the past decade on most modern ships due to different loading techniques. Previously the gauging was done manually with the mate looking down through the ullage hole or hatch. Due to the high loading capacity the emission of cargo vapours through these openings was high. In modern ships the gauging is done by instruments-for example, radar-and thus the exposure during loading is much lower. Measurements (4 hours) done in 1995 on a Swedish coastal tanker loading gasoline showed concentrations of benzene in the range of $0.05-0.6 \mathrm{mg} / \mathrm{m}^{3}$ (mean $0.22 \mathrm{mg} / \mathrm{m}^{3}, \mathrm{n}=5$ ). During unloading the concentrations ranged between 0.06 and $2.1 \mathrm{mg} / \mathrm{m}^{3}$ (mean $0.7 \mathrm{mg} / \mathrm{m}^{3}, \mathrm{n}=8$ ). A benzene concentration ( 1 hour) of $16.6 \mathrm{mg} / \mathrm{m}^{3}$ was measured in the breathing zone of a mate during cleaning of tanks that had contained gasoline (Rolf Nordlinder, personal communication).

This work was funded by a grant from the Swedish Work Environment Fund. We thank Walter Nilsson, Helsingborg, for using his register of Swedish ships and Johan Bagge at the Swedish his register of Swedish ships and Johan Bagge at the Swedish School of Public Health for statistical advice and Mrs Kristina 
Wass, Mrs Birgitta Olofsson, and Mrs Lena Helgesson for assistance in obtaining the exposure data and for secretarial assistance.

1 Nilsson RI, Carneskog I, Järvholm BG, et al. Acute non-lymphatic leukemia among deck officers on coastal tank.

2 Moen BE, Riise T, Helseth A. Cancer among captains and mates on Norwegian tankers. APMIS 1990;98:185-90.

3 Moen BE, Riise T, Helseth A. Mortality among seamen with special reference to work on tankers. Int F Epidemiol 1994; 23:737-41

4 Moen BE. Work with chemicals on the deck of Norwegian chemical tankers. Int Arch Occup Environ Health 1991;62 543-7.

5 Nilsson R, Nordlinder R, Högstedt B, et al. Symptoms, lung and liver function, blood counts, and genotoxic effects in coastal tanker crews. Int Arch Occup Environ Health 1997;69:392-8.

6 Astleford WJ, Bass RL, Buckingham JC, et al. A crew exposure study - phase I, volume II-at sea. St Antonio, Texas: Southwest Research Institute; 1982. (Report No CG-D22-82.)

7 Nordlinder R, Ramnäs O. Exposure to benzene at different work places in Sweden. Ann Occup Hyg 1987;31:345-55.

8 Moen BE, Hollund BE, Berntsen M, et al. Exposure of the Moen $\mathrm{BE}$, Hollund BE, Berntsen $\mathrm{M}$, et al. Exposure of the
deck crew to carcinogenic agents on oil product tankers. deck crew to carcinogenic agents

9 IARC Working Group on the Evaluation of Carcinogenic Risks to Humans (1982 Lyon). Benzene. Some industrial chemicals and dyestuffs. LARC Monogr Eval Carcinog Risks Hum 1982;29:93-148.

10 Aksoy M. Malignancies due to occupational exposure to benzene. Am F Ind Med 1985;7:395-402.

$11 \mathrm{La}$ Vecchia C, Negri E, D'Avanzo B, et al. Occupation and lymphoid neoplasms. Br f Cancer 1989;60:385-8.

12 Rinsky RA, Smith AB, Hornung R, et al. Benzene and leukemia. An epidemiologic risk assessment. $N$ Engl f Med 1987;316:1044-50.

13 Infante PF. Benzene and leukemia: cell types, latency and amount of exposure associated with leukemia. In: Imbriani $\mathrm{M}$, Ghittori S, Pezzagno G, et al, eds. Update on benzene. Advances in occupational medicine and rehabilitation. Pavia, Advances in occupational medicine and rehabilitation. Pavia, Italy:

14 Hayes RB, Yin S-N, Dosemeci M, et al. Benzene and the dose-related incidence of hematologic neoplasms in China. f Natl Cancer Inst 1997;89:1065-71.
15 Socialstyrelsen. National board of health and welfare. The Cancer Registry. Cancer incidence in Sweden 1980. Solna: Socialstyrelsen, 1983.

16 Mattson B. Bortfallet vid registrering $i$ Svenska Cancerregistret. Stockholm: Statistiska Centralbyrån; 1977. (Statistiska meddelanden $H S, 1977: 15$.)

17 Brivkalne M. Kontrollundersökning $i$ samband med 1960 års folkräkning. Stockholm: National Central Bureau of Statistics; 1964. (Statistiska meddelanden B 1964:16.)

18 Wong O. Risk of acute myeloid leukaemia and multiple myeloma in workers exposed to benzene. Occup Environ Med 1995;52:380-4.

19 Savitz DA, Andrews KW. Risk of myelogenous leukaemia and multiple myeloma in workers exposed to benzene [correspondence]. Occup Environ Med 1996;53:357.

20 Savitz D, Andrews KW. Review of epidemiologic evidence on benzene and lymphatic and hematopoietic cancers. $A m$ f Ind Med 1997;31:287-95.

21 Wong O. Risk of myelogenous leukaemia and multiple myeloma in workers exposed to benzene [author's reply]. Occup Environ Med 1996;53:357-8.

22 Wong O. An industry wide mortality study of chemical workers occupationally exposed to benzene. II: Dose response analyses. Br f Ind Med 1987;44:382-95.

23 Aksoy M. Hematotoxicity and carcinogenicity of benzene. Environ Health Perspect 1989;82:193-7.

24 McMichael AJ, Spirtas R, Kupper LL, et al. Solvent exposure and leukemia among rubber workers: an epidemiologic study. F Occup Med 1975:17:234-9.

25 Wong O, Harris F, Smith TJ. Health effects of gasoline exposure. II. Mortality patterns of distribution workers in the United States. Environ Health Perspect Suppl 1993; 101 (suppl 6):63-76.

26 Schwartz E. Proportionate mortality ratio analysis of automobile mechanics and gasoline service station workers in New Hampshire. Am f Ind Med 1987;12:91-9.

27 Infante PF. Benzene in petrol: a continuing hazard. Lancet 1990;336:814-5.

28 Schnatter R, Katz AM, Nicolich MJ, et al. A retrospective mortality study among Canadian petroleum marketing and distribution workers. Environ Health Perspect Suppl 1993; 101(suppl 6):85-99.

29 National Central Bureau of Statistics. Navigation 1960. Official Statistics of Sweden. Transport and communications. Stockholm: National Central Bureau of Statistics, 1962.

30 Statistics Sweden. Navigation 1980. Official Statistics of Sweden. Transport and communications. Stockholm: Statistics Sweden, 1982. 